\title{
ANALISIS TRUCK ROUND TIME DI LAPANGAN IMPOR DALAM KEGIATAN DELIVERY DI PT. MUSTIKA ALAM LESTARI
}

\author{
Intan Nurhaliza ${ }^{1}$, Dadang Suyadi $\mathrm{S}^{2}$ \\ Email : Intannurhaliza16@gmail.com ${ }^{1}$, dsyd@unj.ac.id ${ }^{2}$ \\ Prodi D III Transportasi, Fakultas Teknik - Universitas Negeri Jakarta \\ Prodi D III Transportasi, Fakultas Teknik - Universitas Negeri Jakarta
}

\begin{abstract}
Abstrak. Pada dasarnya dalam kegiatan delivery, consignee menyerahkan SP2 (Surat Penarikan Petikemas) di gate in, kemudian apabila tidak sesuai dengan SP2 maka dikembalikan kepada consignee, apabila sesuai maka dilakukan gate in transaction, kemudian consignee dapat segera menerima petikemasnya seuai lokasi penumpukan yang tertera di SP2, hal tersebut dimaksudkan agar consignee dapat dengan cepat mengeluarkan petikemasnya dari lapangan penumpukan dan truk tidak perlu berlama-lama berada di dalam terminal petikemas. Optimalnya waktu yang cepat dibutuhkan pelayanan yang memadai, tingkat pelayanan yang cepat sangat berpengaruh terhadap optimalnya Truck Round Time dalam kegiatan delivery._Semakin cepatnya Truck Round Time maka semakin optimalnya proses kegiatan delivery dan sebaliknya, dari hasil pengamatan, penulis menemukan masalah yaitu salah satunya petikemas yang akan diambil oleh consignee tidak sesuai dengan lokasi yang tertera di SP2 karena telah mengalami perubahan posisi yang tidak diperbaharui oleh petugas lapangan dan tingginya Yard Occupancy Ratio (YOR) maupun berbarengannya kegiatan delivery dengan kegiatan bongkaran dari kapal. Pada akhir tulisan ini, penulis memberikan kesimpulan beberapa faktor dominan penyebab lamanya waktu yang dibutuhkan oleh consignee untuk mengambil petikemas nya, yaitu kurangnya rasa disiplin dari petugas lapangan untuk memperbaharui posisi terbaru petikemas, tingginya YOR dan berbarengannya waktu kegiatan delivery dengan waktu bongkaran dari kapal. Selain itu penulis juga memasukan beberapa saran kepada terminal atas faktor - faktor yang memperlambat kegiatan delivery. diharapkan dengan saran tersebut dapat bermanfaat untuk perbaikan dari kondisi yang telah ada saat ini.
\end{abstract}

\section{Kata kunci :Truck round time, delivery, Yard Occupancy Ratio}

\begin{abstract}
Basically, in a activity delivery, the consignee submits SP2 (Container Withdrawal Letter) at the gate, then if it is not in accordance with SP2, it is returned to the consignee, if appropriate, the carried out gate in transaction is, then the consignee can immediately receive the container according to the stacking location listed on SP2 This is intended so that the consignee can quickly dispense the container from the stacking field and the truck does not need to be lingering in the container terminal. The optimal time required for adequate service, fast service levels greatly affect the optimal Truck Round Time inactivities delivery. The faster the Round Time Truck, the more optimal process delivery and vice versa, from observations, the authors found a problem that one of the containers to be taken by the consignee was not in accordance with the location listed in SP2 because it had undergone a change in position that was not updated by field officers and high delivery and activities chunk of the ship. At the end of this paper, the authors conclude several dominant factors causing the length of time needed by the consignee to take the container, namely the lack of discipline of field officers to renew the latest container position, the height of Yard Occupancy Ratio (YOR) and concurrently the time of activities delivery with time off from the ship. In addition, the author also included a number of suggestions to the terminal on the factors that slowed activities delivery. It is expected that this suggestion can be useful for improvement of the conditions that already exist today.
\end{abstract}

keywords :Truck round time, Delivery, Yard Occupancy Ratio

\section{A. PENDAHULUAN}

Pelabuhan merupakan salah satu sub sistem dari sistem transportasi laut yang memegang peran penting dalam bidang jasa pelayanan, perkembangan industri, perdagangan, pintu gerbang kegiatan perekonomian daerah, nasional dan internasional. Pelabuhan juga merupakan salah satu mata rantai yaitu proses transportasi dari tempat asal ke tempat tujuan, menampung pangsa pasar yang semakin meningkat dari lalu lintas (traffic) internasional baik transhipment ataupun barang masuk. Seiring dengan perkembangan kemajuan teknologi yang semakin pesat, sistem pengangkutan barang dengan menggunakan petikemas sangat diminati oleh para pengguna jasa angkutan laut. Sarana tersebut dinilai dapat menjamin keutuhan dan keselamatan barang, serta dapat memenuhi ketepatan waktu pengiriman barang. Sistem pengangkutan dengan menggunakan petikemas berkembang sangat pesat di seluruh dunia termasuk Indonesia, untuk mewujudkan efisiensi dan efektifitas dalam penggunaannya, maka sistem pengangkutan dengan menggunakan petikemas ini harus di dukung oleh suatu sub lainnya, salah satunya adalah terminal petikemas.

Terminal petikemas merupakan suatu fasilitas yang disediakan oleh perusahaan yang bergerak dibidang bongkar muat barang secara cepat, pengoprasian bongkar muat harus dilakukan secara efektif, efisien dan profesional sehingga pelayanan pelabuhan menjadi lancar, aman dan cepat dengan biaya yang terjangkau. Fungsi pelabuhan sendiri juga merupakan tempat pertemuan (interface) dua moda angkutan atau lebih serta interface berbagai 
kepentingan yang saling terkait. Barang yang diangkut dengan kapal akan dibongkar dan dipindahkan ke moda lain seperti (truk atau kereta api), sebaliknya barang yang diangkut dengan truk atau kereta api ke pelabuhan bongkar akan dimuat lagi ke kapal.

Kekurangan menggunakan petikemas itu sendiri yaitu membutuhkan dana yang besar dalam pengoperasiannya dan dalam pengadaan alat-alat pendukung seperti alat bongkar muat petikemas serta pembangunan sebuah terminal petikemas untuk mendukung proses kegiatan bongkar muat tersebut. Dalam kegiatan delivery, truck round time juga sangat berpengaruh, lamanya waktu truk di lapangan penumpukan tidak sesuai dengan idealnya waktu truk di lapangan penumpukan sehingga dapat menyebabkan terhambatnya kegiatan delivery barang dan bertambah besarnya waktu truk menunggu petikemas. Kondisi ini perlu dihindari karena akan meningkatkan nilai dari truck round time yang merupakan indikator dari efisiennya kegiatan delivery dalam sebuah terminal peti kemas. Hal tersebut tentunya akan mengakibatkan penurunan citra dari terminal itu sendiri.

\section{B. METODE PENELITIAN}

PT. Mustika Alam Lestari merupakan perusahaan bongkar muat yang menangani salah satunya yaitu kegiatan delivery, untuk menghasilkan optimalnya waktu yang cepat dan efisien dalam kegiatan delivery dibutuhkan pelayanan yang optimal, cepat dan tepat sehingga dapat menghasilkan proses kegiatan delivery yang lancar dan optimal. Penyediaan fasilitas sarana dan prasarana pelayanan yang memadai merupakan suatu keharusan yang sangat perlu diperhatikan bagi perusahaan itu sendiri, terutama dalam memberikan kepuasan kepada pengguna jasa khususnya dalam penanganan bongkar muat, delivery dan receiving.

Tingkat pelayanan yang cepat sangat berpengaruh terhadap optimalnya truck round time dalam kegiatan delivery. Semakin cepatnya truck round time, maka semakin optimalnya proses kegiatan delivery. Sebaliknya apabila semakin lama waktu truk di dalam lapangan penumpukan, maka semakin tidak optimalnya dalam proses kegiatan delivery. Dari hasil pengamatan, penulis menemukan masalah yaitu lamanya truk di lapangan penumpukan yang disebabkan tingginya YOR yang membuat target TrRT menurun dan berbarengannya waktu kegiatan delivery dengan kegiatan bongkaran kapal dapat memperlambat waktu truk di lapangan penumpukan, penuhnya lapangan penumpukan membuat aktifitas di lapangan menjadi sedikit terhambat, karena harus lebih mengantri untuk mengambil petikemas nya dari lapangan penumpukan, letak petikemas yang akan diambil oleh consignee tersebut terkadang tidak sesuai dengan SP2 yang tertera/ yang dibawa oleh supir truk yaitu karena petugas lapangan yang tidak mengupdate posisi petikemas setelah kegiatan lift on dan lift off.

\section{A. Data Primer}

Data primer adalah data yang diperoleh peneliti secara langsung. Observasi truk di lapangan penumpukan lamanya waktu truk yang melebihi waktu ideal truk selama di lapangan penumpukan, melihat antrian truk yang akan masuk ke lapangan penumpukan karena tingginya YOR, maksimal jumlah tier di PT. MAL sejumlah 6 tier.

\section{B. Data Sekunder}

Data sekunder adalah data yang didapat di objek penelitian yang telah dicatat berupa dokumentasi yang telah tersusun secara sistematis dan dapat digunakan sebagai bahan acuan atau referensi dalam penelitian, data tersebut antara lain:

1. Data Truck Round Time yang ideal.

2. Presentase TrRT dan YOR selama 1 tahun pada tahun 2018. 


\section{HASIL DAN PEMBAHASAN}

Berikut merupakan data TrRT yang ideal:

Tabel 1. TrRT yang Ideal

\begin{tabular}{|c|c|}
\hline KEGIATAN & LAMA WAKTU \\
\hline Gate Transaction & $<5$ menit \\
\hline Trucking menuju lapangan impor & $<15$ menit \\
\hline Lift On & $<15$ menit \\
\hline Trucking lapangan impor menuju Gate Out & $<15$ menit \\
\hline TOTAL & $<60$ menit \\
\hline
\end{tabular}

Berikut merupakan data TrRT selama 1 tahun:

Tabel 2 Data TrRT Per-Bulan Selama 1 Tahun

\begin{tabular}{|c|c|c|c|c|c|}
\hline \multirow{2}{*}{ No } & Bulan & $\begin{array}{c}\text { Delivery } \\
(\mathrm{bxs})\end{array}$ & $\begin{array}{c}\text { Delivery } \\
60 \text { mins } \\
\text { (bxs) }\end{array}$ & $\begin{array}{l}\text { Average } \\
\text { (time) }\end{array}$ & $\begin{array}{l}\text { \% Meet } \\
\text { target }\end{array}$ \\
\hline 1 & Januari & 10057 & 2759 & 28,60 & $72,57 \%$ \\
\hline 2 & Februari & 7674 & 1511 & 27,19 & $80,31 \%$ \\
\hline 3 & Maret & 6638 & 1339 & 23,02 & $79,83 \%$ \\
\hline 4 & April & 5976 & 1030 & 25,43 & $82,76 \%$ \\
\hline 5 & Mei & 5457 & 645 & 20,99 & $88,18 \%$ \\
\hline 6 & Juni & 4524 & 1527 & 29,06 & $66,25 \%$ \\
\hline 7 & Juli & 10714 & 2992 & 30,53 & $72,07 \%$ \\
\hline 8 & Agustus & 9466 & 2775 & 25,97 & $70,68 \%$ \\
\hline 9 & September & 10766 & 3102 & 30,06 & $71,19 \%$ \\
\hline 10 & Oktober & 11335 & 3990 & 29,71 & $64,80 \%$ \\
\hline 11 & November & 10596 & 4406 & 33,93 & $58,42 \%$ \\
\hline 12 & Desember & 8110 & 1999 & 23,31 & $75,35 \%$ \\
\hline & Total & $\mathbf{1 0 1 3 1 3}$ & $\mathbf{2 8 0 7 5}$ & $\mathbf{2 7}$ & $\mathbf{7 2 , 2 9 \%}$ \\
\hline
\end{tabular}

Dari tabel di 2 dapat disimpulkan bahwa TrRT dalam 1 tahun pada tahun 2018 baru 72,29\% yang mencapai target idealnya TrRT di lapangan penumpukan. TrRT yang paling tinggi mencapai target berada pada bulan Mei sebanyak $88,18 \%$, TrRT yang paling rendah berada pada bulan November yaitu hanya 58,42\% yang mencapai target.

Tabel 3 Data YOR 2018 Lapangan Penumpukan PT. Mustika Alam Lestari

\begin{tabular}{|l|c|c|}
\hline No & Bulan & Impor $(\%)$ \\
\hline 1 & Januari & 65,00 \\
\hline 2 & Februari & 63,97 \\
\hline 3 & Maret & 44,82 \\
\hline 4 & April & 49,94 \\
\hline 5 & Mei & 41,92 \\
\hline 6 & Juni & 51,76 \\
\hline 7 & Juli & 71,41 \\
\hline 8 & Agustus & 71,25 \\
\hline 9 & September & 67,65 \\
\hline 10 & Oktober & 59,33 \\
\hline 11 & November & 78,40 \\
\hline 12 & Desember & 53,89 \\
\hline
\end{tabular}


YOR paling tinggi berada pada bulan November dan paling rendah berada pada bulan Mei, sebaliknya TrRT paling rendah berada pada bulan Mei sedangkan TrRT paling tinggi berada pada bulan November, maka bisa disimpulkan bahwa TrRT dan YOR berhubungan, tingginya suatu YOR dapat mempengaruhi lamanya waktu truk didalam lapangan penumpukan. Pada bulan November target TrRT yang dicapai oleh PT. MAL hanya 58,42\%.

Proses penerbitan surat penyerahan petikemas (SP2),menurut data diatas loket Impor menerima Delivery Order Asli (DO.A) dan Surat Persetujuan Pengeluaran Barang Fiat Beacukai SPPB.F) dari Pengguna Jasa untuk penerbitan nota penumpukan dan gerakan (Lift On) lalu kasir menerima pembayaran dari Pengguna Jasa untuk pelunasan Nota dan menyerahkan Nota Lunas Asli (NL.A) kepada Pengguna Jasa. Selesai melakukan pembayaran, Pengguna Jasa menuju Loket Impor dengan membawa NL atas dasar DO.A, NL.C dan SPPB.FC, Petugas Loket Impor menerbitkan SP2, setelah diverifikasi SP2 ditandatangani kemudian diserahkan ke Pengguna Jasa.

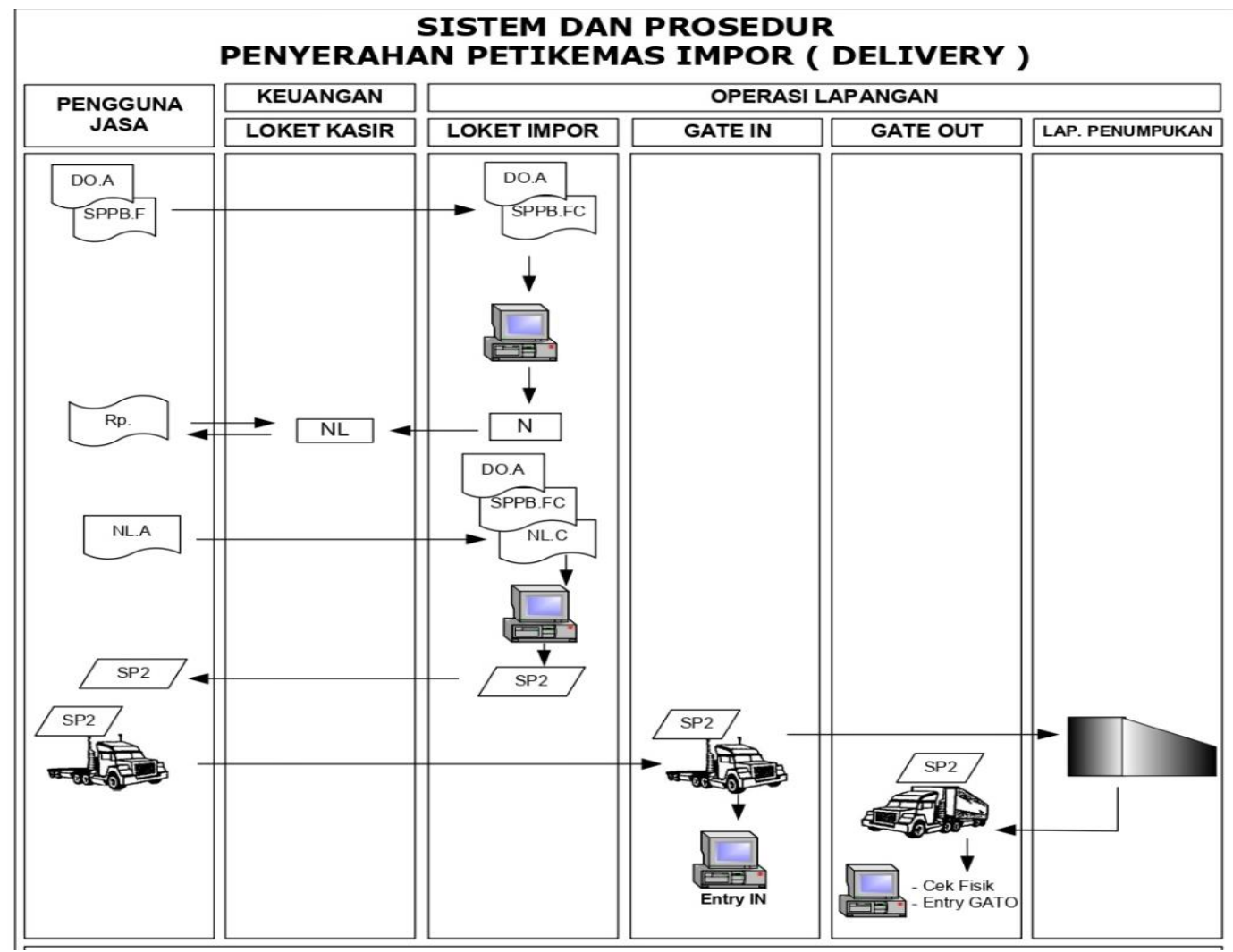

Gambar 1 Sistem dan prosedur kegiatan delivery

Sumber : PT. Mustika Alam Lestari

1. Loket Impor menerima Delivery Order Asli (DO.A) dan Surat Persetujuan Pengeluaran Barang Fiat Beacukai (SPPB.F) dari Pengguna Jasa untuk penerbitan nota penumpukan dan gerakan (Lift On).

2. Kasir menerima pembayaran dari Pengguna Jasa untuk pelunasan nota dan menyerahkan Nota Lunas Asli (NL.A) kepada Pengguna Jasa.

3. Selesai melakukan pembayaran, Pengguna Jasa menuju Loket Impor dengan membawa NL.

4. Atas dasar DO.A, NL.C dan SPPB.FC, Petugas Loket Impor menerbitkan SP2, setelah diverifikasi SP2 ditandatangani kemudian diserahkan ke Pengguna Jasa.

5. Pengguna Jasa menyerahkan SP2 ke sopir truk untuk mengambil petikemas dari Terminal Petikemas.

6. Petugas Gate In memeriksa dan kemudian melakukan Entry IN.

7. Petugas Lapangan melaksanakan pemuatan petikemas ke atas chassis truck sesuai SP2.

8. Petugas Gate Out melakukan cek fisik dan segel petikemas serta mengisi hasil cek fisik pada EIR yang tercantum dalam SP2, kemudian melakukan Entry Gate Out .

9. Sopir Truk membawa petikemas ke lokasi yang dituju sesuai SP2.

\section{Berikut Pokok Permasalahan :}

Pada kegiatan delivery ada faktor yang dapat menghambat kelancaran kegiatan delivery itu sendiri seperti diketahui bahwa tolak ukur dari kelancaran kegiatan delivery yaitu lamanya waktu yang diperlukan oleh truk untuk mengambil petikemas nya yang dihitung sejak truk tersebut memasuki dan dilayani oleh petugas gate in sampai truk tersebut 
dilayani di gate out, waktu tersebut biasa disebut dengan Truck Round Time (TrRT).

Permasalahan yang terjadi disini adalah TrRT yang masih melebihi waktu ideal yang telah ditentukan oleh PT.MAL itu sendiri yaitu selama $<60$ menit didalam lapangan penumpukan. Kegiatan yang mempengaruhi truck round time disebabkan oleh tingginya YOR sehingga membuat antrian truk yang akan mengambil petikemas nya di lapangan penumpukan, dan waktu kegiatan delivery tersebut berbarengan dengan waktu bongkaran kapal, kurang disiplinnya petugas lapangan yang tidak mengupdate letak posisi petikemas setelah sebelumnya petugas lapangan melakukan kegiatan lift on dan lift off.

\section{Berikut Uraian permasalahan:}

Idealnya Truck Round Time (TrRT) yang dibutuhkan untuk mengambil petikemas nya yaitu sebagai berikut:

Tabel 4 waktu TrRT yang ideal

\begin{tabular}{|c|c|}
\hline KEGIATAN & LAMA WAKTU \\
\hline Gate Transaction & $<5$ menit \\
\hline Trucking menuju lapangan impor & $<15$ menit \\
\hline Lift On & $<15$ menit \\
\hline Trucking lapangan impor menuju Gate Out & $<15$ menit \\
\hline TOTAL & $<60$ menit \\
\hline
\end{tabular}

Pada realisasi nya lama truck round time tidaklah sesuai dengan waktu ideal yang diharapkan seperti tabel 3.4, terkadang TrRT melebihi waktu ideal, bahkan jauh melebihi dari waktu ideal. Kenyataan tersebut lebih terlihat pada kegiatan delivery petikemas impor, dimana waktu TrRT yang dibutuhkan dalam kegiatan delivery petikemas impor banyak yang melebihi waktu ideal dari TrRT tersebut.

Dari hasil data tabel 3.2 dan 3.3 penulis akan membuat diagram YOR dilapangan penumpukan dan $\operatorname{TrRT}>60$ menit dalam 1 tahun di tahun 2018 yang dimana YOR mempengaruhi lamanya TrRT di dalam lapangan penumpukan karena penuhnya antrian truk yang ingin mengambil petikemas nya di lapangan penumpukan, maupun berbarengannya waktu untuk pengambilan petikemas dengan kegiatan bongkaran petikemas dari kapal, sehingga menghambat kegiatan delivery.

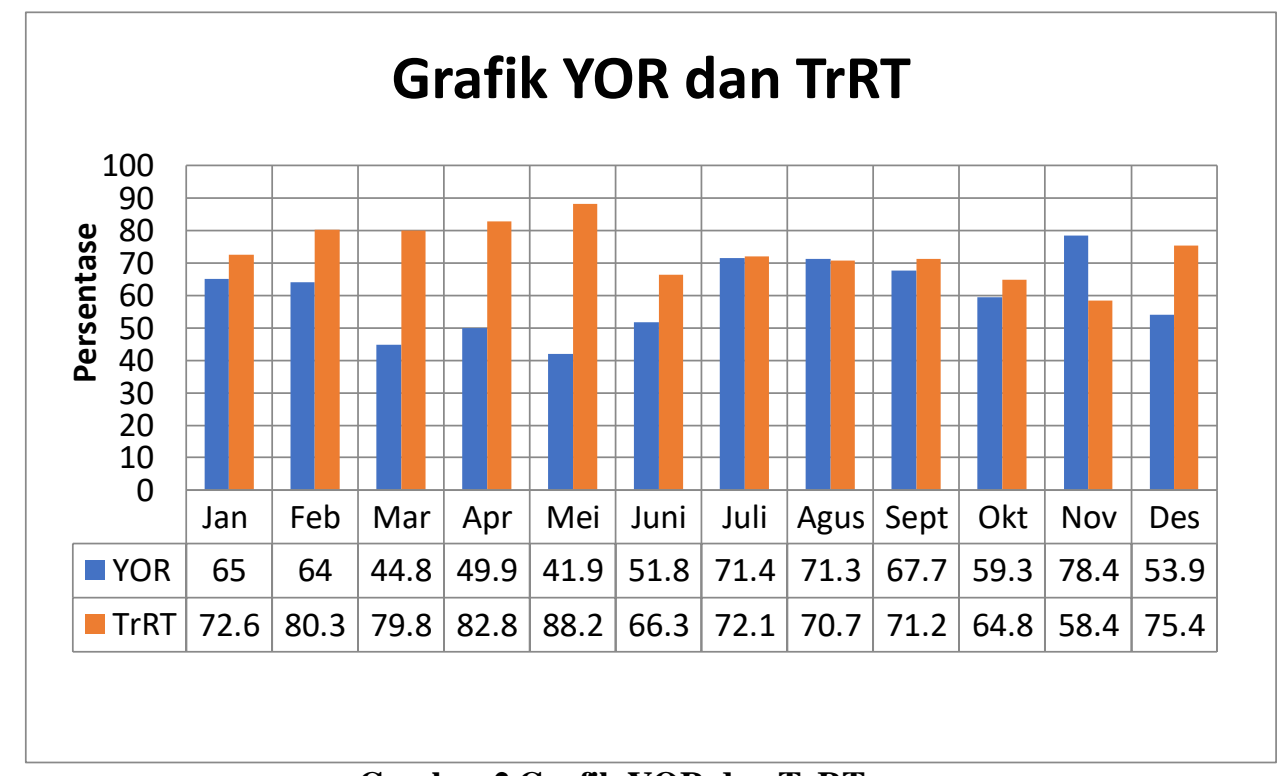

\section{Gambar 2 Grafik YOR dan TrRT}

Dari grafik pada gambar 3.2 dapat disimpulkan bahwa pelayanan dari kegiatan delivery masih banyak yang belum mencapai target ideal jika dilihat dari lamanya TrRT yang $<60$ menit, data truck round time yang $>60$ menit paling banyak berada pada bulan November, hanya $58,42 \%$ yang mencapai target idealnya truk didalam lapangan penumpukan.

Ideal dan tidaknya TrRT yang mempengaruhi kegiatan delivery merupakan kendala tersendiri dalam memberikan pelayanan terhadap pengguna jasa, dari permasalahan yang timbul dalam kegiatan delivery petikemas impor tersebut terdapat pokok permasalahan yaitu tingginya YOR di lapangan penumpukan dan terkadang waktu kegiatan delivery tersebut bersamaan dengan proses bongkar dari kapal sehingga truk luar terhambat dengan truk bongkaran, faktor 
kelalaian, dan tidak disiplin nya petugas lapangan dalam memperbaharui letak posisi petikemas terbaru setelah melakukan lift on dan lift off, akibatnya berdampak pada lamanya proses kegiatan delivery dan akan menurunnya kepuasan dari pelanggan atau pengguna jasa.

\section{Berikut Solusi Masalah:}

TrRT yang melebihi waktu ideal yang telah ditentukan akan berdampak negatif baik pada pihak PT.MAL dan pihak pengguna jasa untuk meminimalisir besarnya TrRT dalam kegiatan delivery perlu kesadaran dan kerjasamanya yaitu dalam disiplin kerja dan peraturan-peraturan akan sanksi yang harus dilakukan sebagaimana mestinya agar bisa lebih maksimal dalam kegiatan delivery, petugas gate in harus berkoordinasi dengan petugas lapangan untuk membatasi truk eksternal yang akan masuk ke lingkungan PT.MAL agar bergantian sehingga tidak memakan waktu lama di dalam lapangan penumpukan tersebut.

\section{KESIMPULAN}

Dari hasil pengamatan, maka penulis mengambil kesimpulan sebagai berikut:

1. Belum optimalnya Truck Round Time dalam kegiatan delivery petikemas impor yang dapat menghambat kelancaran dari kegiatan itu sendiri, tingginya YOR di lapangan penumpukan, berbarengannya kegiatan delivery dengan waktu bongkaran kapal sehingga banyak truk di lapangan penumpukan yang sedang beroperasi, lokasi petikemas impor terkadang tidak sesuai dengan SP2 yang dibawa oleh supir truk sehingga dapat menyebabkan terhambatnya kegiatan delivery dan semakin bertambahnya waktu truk di lapangan penumpukan.

2. Pelayanan dari kegiatan delivery masih kurang dari ideal jika dilihat dari lamanya waktu truk di lapangan penumpukan yang dimana Truck Round Time yang hanya 72,29\% yang mencapai target.

Kurangnya rasa disiplin dari petugas lapangan yang bertugas untuk memberitahukan posisi terbaru dari petikemas impor yang merupakan faktor lain yang dapat menyebabkan sulit ditemukannya petikemas itu sendiri sehingga dapat memperlambat kegiatan delivery petikemas impor tersebut.

\section{E. SARAN}

Berdasarkan pembahasan yang telah disampaikan sebelumnya, maka saran yang dapat penulis sampaikan antara lain:

1. Membatasi truk eksternal yang akan masuk ke lingkungan PT.MAL agar bergantian sehingga tidak memakan waktu lama di dalam lapangan penumpukan tersebut.

2. Melakukan pemeriksaan dan pembaharuan data petikemas kembali pada saat melakukan lift on dan lift off.

3. Pihak manajemen memberikan motivasi yang diberikan untuk petugas - petugas lapangan agar dapat mendukung serta menunjang kedisiplinan, gairah kerja atau kelancaran tugas dan memberikan penghargaan bagi karyawan yang baik dalam kerjanya dan memberikan denda bagi karyawan yang kurang maksimal dalam kerjanya, hal ini tentunya sangat berpengaruh besar dalam merangsang kedisiplinan semangat bekerja petugas lapangan, sehingga produktivitas kerja meningkat.

\section{F. DAFTAR PUSTAKA}

[FT] Fakultas Teknik, 2015. Buku Panduan Penyusunan Tugas Akhir. Jakarta: Fakultas Teknik, Universitas Negeri Jakarta.

Lasse, D. A 2016. Manajemen Muatan Aktifitas Rantai Pasok Di Area Pelabuhan. Jakarta: RajaGrafindo Persada.

[MAL] Mustika Alam Lestari, 2018 Terminal Operational System. Jakarta: PT. Mustika Alam Lestari. Nugraha, Artha, 2016. Mengenal Petikemas Atau Kontainer- Referensi Logistik Indonesia. Sumber: https://www.arthanugraha.com/mengenal-peti-kemas-kontainer/. Diakses pada 12 Juli 2019.

Sibawaih, Hamid. 2004. Pengertian Profesi. Sumber: https://www.academia.edu/8096122/Pengertian_Profesi. Diakses 12 Juli 2019.

Suyono, R. P 2005. Shipping Pengangkutan Intermoda Ekspor Impor Melalui Laut. Jakarta 

